\title{
Temaprediking uit die Nuwe Testament
}

\author{
GMM Pelser
}

\begin{abstract}
Preaching themes from the New Testament

The issue addressed in this essay is the question as to the legitimacy and possibility of theme preaching from the New Testament in view of the indisputable diversity in the New Testament. After having given some illustrations of thematic diversity in the New Testament, a number of guidelines is drawn comprising in substance the following: the thematic diversity, and in some cases irreconcilability, in the New Testament should be regarded as a fact and may not be ignored; diversity per se should not, however, be viewed negatively; every witness should be treated separately and independently; as far as two or more witnesses concur, they may be treated jointly; one should not attempt to dissolve the diversity by means of harmonisation; in those cases, however, where witnesses contradict one another, a choice between them will, depending on one's theological point of view, be unavoidable.
\end{abstract}

\section{INLEIDEND}

Solche Variabilität (van die vroeg-christelike kerugma) ist jedoch bereits im NT so gross, dass wir nicht nur erhebliche Spannungen, sondern nicht selten auch unvereinbare theologische Gegensätze zu konstatieren haben . . . Die Variabilität des Kerygmas im NT ist Ausdruck des Tatbestandes, dass bereits in der Urchistenheit eine Fülle verschiedener Konfessionen nebeneinander vorhanden war, aufeinander folgte, sich miteinander verband und gegeneinander abgrenzte ( Käsemann 1960: 218, 221 resp).

Das Bild, dass das Neue Testament von der Urchristenheit wiederspiegelt, zeigt deutlich dass die frühe Kirche keine einheitliche Grösse gewesen ist. Vielmehr ist von Anfang an Vielfalt

* Referaat gelewer op 14 Oktober 1986 as deel van die seminaarreeks in die Fakulteit Teologie (Afd A), Universiteit van Pretoria, aangebied deur die Departemente OuTestamentiese Wetenskap en Nuwe-Testamentiese Wetenskap. 
legitimer Ausdruck der Gestaltung christlichen Glaubens gewesen (Lohse 1982: 12).

We can no longer doubt that there are many different expressions of Christianity within the NT ... and when we compare these patterns we find that by no means did they always complement each other; on the contrary, they not infrequently clashed, sometimes fiercely ... We must conclude therefore that there was no single normative form of Christianity in the first century .... In view of this sharply contrasting picture (minimal unity, wide-ranging diversity), what continuing value has the canon? Since the NT is not a homogeneous collection of neatly complementary writings, can we any longer speak of 'the NT teaching' on this or that? (Dunn 1977: 372, 373, 374 resp).

Uit bogenoemde en talle ander stellings van verskeie hedendaagse Nuwe-Testamentici blyk meer as duidelik dat dit vandag onmoontlik geword het om iets oor die teologie van die Nuwe Testament te probeer kwytraak sonder om minstens eers kennis te neem van die verskeidenheid wat daar in die Nuwe Testament aanwesig is oor haas elke, indien nie alle teologiese temas nie. En dieselfde sou vanselfsprekend geld vir 'n poging om oor Nuwe-Testamentiese temas te preek. Hierdie insig in verband met die verskeidenheid, en selfs teenstrydigheid, van teologieë of teologiese temas in die Nuwe Testament is natuurlik nie nuut nie. Ons kan met reg sê dat reeds die vroeg-kerklike worstelgeskiedenis tot kanonvorming of -afgrensing ' $n$ illustrasie hiervan is, en ' $n$ mens herinner jou ook die tendenskritiek waaraan FC Baur die geskrifte van die Nuwe Testament onderwerp het.

Hierdie verskeidenheid is natuurlik nie slegs toe te skryf aan verskeie afsonderlike en onafhanklike teologiese refleksies oor die Christusgebeure en die daaruit voortvloeiende persoonlike en kerklike Existenzverständnis van gelowiges nie. Dit is ook toe te skryf aan ontwikkeling wat ingetree het as gevolg van die verloop van tyd en verandering van situasie. Die evangelie en wat daarvan geglo en verstaan is, moes dus telkens in 'n nuwe tyd en situasie tot 'n eksistensiële ervaring vir gelowiges word. In die proses van 'teologisering' in die vroegste kerk het sekere geloofsinteresses ' $n$ rol gespeel, het beïnloeding plaasgevind, was daar kragte binne- en buite-gemeentelik aan die werk en het bepaalde agtergronde ' $n$ bydrae gelewer. En met dit alles is gepoog om 'n geloofsantwoord te probeer gee op die een sentrale gebeure, die 
Christus-gebeure, en hoe dit dié raak wie se lewe daardeur in beslag geneem is.

\section{ENKELE VOORBEELDE}

\subsection{Die Christologie}

Hoewel dit onder die oorkoepelende tema 'Die Christologie van die Nuwe Testament' om veel meer gaan as Christologiese titels, word hier slegs tema- en titel-gewys op 'n paar verskille gewys.

\subsubsection{Pre-eksistensie}

Terwyl Paulus, Johannes en hoogs waarskynlik ook Markus Christologies uitgaan van die pre-eksistensie van Christus, vind ons by Matteus en Lukas niks hiervan nie. Dit blyk naamlik uit die geboortevertelling van beide Matteus en Lukas dat Jesus nie deur hulle as Seun van God gesien is op grond daarvan dat Hy pre-eksistent was nie, maar omdat die Gees van God mede-verantwoordelik was vir sy geboorte. Aan die ander kant weet Paulus, Johannes en Markus weer niks van die maagdelike geboorte nie.

\subsubsection{Die persoon van Jesus by die sinoptici}

Indien byvoorbeeld Kingsbury (1981) en ander dit reg het, is daar benewens enkele ooreenkomste, tog ook merkbare verskille in die wyses waarop die persoon van Jesus deur die drie sinoptici onderskeidelik geteken word. As ooreenkoms kan aangeteken word dat by al drie die Menseseun-titel as ' $n$ 'openbare' titel funksioneer en nie as ' $n$ belydenis-titel nie, terwyl Seun van God by al drie funksioneer as ' $n$ belydenis-titel.

Hierteenoor: $Q$ verwys nêrens na Jesus as Messias nie, en anders as Markus verbind hy dus nie Seun van God aan Messias nie. Volgens Markus is Jesus die Messias, Seun van God wat aan die kruis moet sterf. Volgens Matteus is Hy die Messias, Seun van God deur wie God naby aan die mense gekom het. Benewens die feit dat Lukas heelwat maak van Jesus as Verlosser en Here, maak hy meer van Jesus as Messias as wat Markus en Matteus doen. Messias en Seun van God word by hom byna sinoniem en die Messias van God funksioneer as die sentrale titel.

Wat die loci van redding betref, is daar ook merkbare verskille: by $Q$ 
is dit die eind-oordeel; by Markus die kruis; by Matteus die teenwoordigheid van die verhoogde Seun van God by sy mense; by Lukas die verkondiging van die verlossing en die lid-word van die kerk. Die kruisdood funksioneer nie vir Lukas as versoening van sondes nie, maar as die God-gewilde vernedering van Jesus.

Soos bekend, het verskeie Nuwe-Testamentici deur middel van historiese ondersoek, en dikwels op goeie gronde, aangetoon dat bepaalde Christologiese titels in bepaalde vroeg-kerklike kringe ontstaan het en slegs daar gefunksioneer het (vgl Bousset 1967; Hahn 1963; Kramer 1963, om slegs 'n paar te noem). Betreklik onlangs nog het Dunn (1977: 58) die saak soos volg gestel:

In oversimplified terms, and leaving aside the Son of Man tradition which was an important expression of the eschatological faith of the earliest community, we may say that 'Jesus is the Messiah' appears to have been die chief confession of Palestinian Jewish Christians, 'Jesus is the Son of God' of Hellenistic Jewish Christians, 'Jesus is Lord' of Gentile Christians.

Indien hierdie bevinding korrek is, kan ons vanselfsprekend hierdie titels streng gesproke nie tuisbring onder die tema Christologie van die vroegste kerk nie, maar wel onder Christologieë van die vroegste kerk.

\subsection{Die doop}

2.2.1 Hoewel die dooppraktyk klaarblyklik van baie vroeg af in die kerk beoefen is, is dit in die eerste plek nie duidelik wat as antesedent of as analogie daarvoor gedien het nie. Dat Jesus die insteller van die doop was, word, soos bekend, slegs deur Matteus berig. Die historiese juistheid van hierdie vermelding is egter onder verdenking vanweë die trinitariese formule wat daarin voorkom. Dit verteenwoordig klaarblyklik 'n latere ontwikkeling, aangesien alle ander getuies slegs die doop in die Naam van Jesus ken (Hand 2: 38; 8: 16; 10: 48; 19: 5; vgl 1 Kor 1: 13, 15; Rom 6: 3; Gal 3: 27).

2.2.2 Dit wil voorkom of die Gees as gawe in die meeste gevalle met die doop verbind is, maar hoe hierdie verhouding in die verskillende kringe presies gesien is, is nie moontlik om met sekerheid uit te maak nie. In Handelinge byvoorbeeld volg die ontvangs van die Heilige Gees op die doop in 2: 38; 8: 12, 16, 17; 19: 5, 6, terwyl dit daaraan voorafgaan in $9: 17 \mathrm{v} ; 10: 44 \mathrm{vv}$ en glad nie vermeld word 
in $8: 38 ; 16: 15,33 ; 19: 8$ nie. (Kyk ook nog Joh 3: 5; 1 Kor 6: 11; 12:13; 2 Kor 1: 22; Ef 1: 13; 4: 30; Tit 3: 5; 1 Pet 1: 2 ; 1 Joh 2: 20). Dit is verder opvallend dat waar in 2 Korintiërs 1: 22 die Gees as gawe volg op die beseëling (handoplegging?) by die doop deur God, die skrywer van die Efesebrief die Gees maak tot die seël self waarmee die dopeling as eiendom van God beseël word (Ef 1: 13; $4: 30$ ). Is dit slegs ' $n$ onbeduidende en oppervlakkige verskil of sit daar veel meer agter?

2.2.3 Terwyl die doop by Handelinge bekering en vergewing van sondes veronderstel en eskatologies gerig is, lyk dit asof die eskatologiese gerigtheid by Paulus nie voorkom nie. Hier is die blik byna uitsluitlik terugwaarts gerig op die dood van Christus en die deel-kry aan die heilsbetekenis van hierdie dood. Hoewel daar in apelousasthe in 1 Korintiërs 6: 11 iets deurskemer van simboliese sondeafwassing, is alles by Paulus gefikseer op die gelowige se solidêr-word met Christus in sy dood en sy een-word met Christus (Rom 6: 3 vv; Gal 3: 27). Dit is opmerklik dat Paulus van die doop baie meer maak as wat byvoorbeeld Handelinge of die res van die Nuwe Testament daarvan maak. Vir hom bring die doop ' $n$ mens in ' $n$ besondere verhouding met Christus, ' $n$ verhouding wat deur die Korintiërs klaarblyklik in magiese sin verstaan en ervaar is (kyk 1 Kor 10: 1 vv; 15: 29). Die skrywer van die Kolossensebrief sluit in hierdie opsig by Paulus aan, maar gaan heelwat verder as Paulus deur die doop te beskryf as die geleentheid waartydens die dopeling ook reeds saam met Christus opgestaan het (Kol 2: 12). Hier word duidelik aan die doop 'n funksie toegeskryf wat 'n baie meer gerealiseerde uitwerking het as wat Paulus bereid was om daaraan toe te ken.

\subsection{Die nagmaal}

Word die nagmaal as tema van prediking geneem, sal 'n mens ook hier bedag moet wees op opvallende en selfs diepgaande verskille. Ek noem slegs die paar belangrikstes.

2.3.1 Markus (gevolg deur Matteus en Lukas) plaas die nagmaalstradisie in 'n paasmaal-raamwerk, terwyl Paulus dit nêrens met die pasga verbind nie. Dit laat die vraag ontstaan na die betekenis wat Markus vanuit die pasga-tradisie aan die nagmaal geheg het, terwyl Paulus daar niks van gemaak het nie. 
2.3.2 Markus se berig bevat nie die anamnēsis opdrag nie, terwyl dit by Paulus by beide die brood- en bekerwoode voorkom. Dui dit by Paulus op 'n betekeniskomponent van die nagmaal wat nie by Markus aanwesig is nie?

2.3.3 Die belangrikste verskil behels egter die formulering van die bekerwoord by Markus en Paulus onderskeidelik: Markus - touto estin to haima mou tès diathèkēs; Paulus - touto ... hè kainē diathēkē estin en tō emō haimati. Hieruit blyk duidelik dat by Markus die parallelle terme sōma en haima is, maar by Paulus sōma en diathēkē. Hoewel haima en diathēkē by albei voorkom, is die sintaktiese ordening daarvan verskillend. Is dit bloot' $n$ sintaktiese verskil sonder semantiese implikasies? Verskeie Nuwe-Testamentici is daarvan oortuig dat dit beslis dui op ' $n$ diepgaande semantiese verskil. 'Dies ist durchaus nicht nur eine belanglose Formulierungsvariante' (Bornkamm 1970: 161). By Markus is haima in fokus, by Paulus diathēkē. Op watter verskil sou dit dan in werklikheid dui? Dit lyk asof Markus 'n opvatting verteenwoordig wat die liggaam en bloed van Christus gesien het as geestelike voedsel en drank vir die gelowige by die nagmaal. Hierteenoor verteenwoordig Paulus 'n opvatting waar daar nie sprake is van geestelike voedsel en drank nie, maar van twee selfstandige handelinge wat elkeen ' $n$ selfstandige gebeure aan die orde stel: die handeling met die brood gee deel aan die heilsbetekenis van Christus se dood; die handeling met die beker gee deel aan die nuwe heilsbedeling wat deur Christus se dood bewerkstellig is (kyk verder Pelser [1975] en [1977]).

\subsection{Die eskatologie}

Seker een van die mees gekompliseerde temas in die Nuwe Testament is dié van die eskatologie. Dit is duidelik dat tyd en omstandighede 'n groot rol gespeel het in die vorming van uiteenlopende beskouings oor die eskatologie en dan by name ook die paroesieverwagting (kyk bv Nineham 1976: $156 \mathrm{vv}$ vir 'n grafiese voorstelling van die modelle). Dit is onmoontlik om binne hierdie bestek breedvoerig op die saak in te gaan en daarom sal 'n paar opmerkings moet voldoen.

2.4.1 Dit blyk dat, terwyl daar in die vroegste stadia 'n sterk Naherwartung van die paroesie bestaan het, hierdie verwagting met die verloop van tyd nie alleen in sekere kringe vervaag het nie, maar in ander selfs met iets anders vervang is. Iets van hierdie nabye verwagting tref ons nog aan by Markus en die vroeëre briewe van 
Paulus, maar reeds by Paulus vind daar ' $n$ verskuiwing plaas. Terwyl hy in 1 Tessalonisense 4: 15, 17 die paroesie nog tydens sy leeftyd verwag en sterfgevalle voor die paroesie as uitsonderlik beskou, beskou hy in 1 Korintiërs 15: 51 sterfgevalle voor die paroesie as normaal en hou hy in 2 Korintiërs 5: 1 vv en Filippense 1: 23 rekening met sy voortydige dood. In Romeine 13: $11 \mathrm{vv}$ spreek hy nog die verwagting uit van die paroesie, maar hy gee geen aanduiding van hoe naby hy dit verwag nie. Hierbenewens het hy reeds ook baie klem begin plaas op die betekenis van die Christusgebeure in die verlede (kyk Pelser 1986).

2.4.2 Lukas-Handelinge het reeds die uitbly van die paroesie as ' $n$ feit aanvaar en die probleem probeer oplos deur die tyd voor die paroesie tot heilsgeskiedenis en tot tyd van die kerk te maak.

2.4.3 In die Kolossense- en Efesebrief word die uitsig op die paroesie teologies prakties betekenisloos en deur ruimtelike voorstellings vervang. Daar is wel nog 'n uitsig op die paroesie maar die klem het verskuif. Vir Kolossense lê die aksent op die hede: dat Christus die gelowige se lewe is en dat die gelowige reeds deel in die heil. Vir Efesiërs lê die klem op die kerk as die oikonomía van God waarin Jood en nie-Jood saam verenig is en wat na die Hoof toe en tot volwassenheid groei.

2.4.4 By die Hebreërbrief is die ruimtelike voorstelling toegevoeg tot die tydsvoorstelling. Wat in die toekoms verwag word, naamlik die hemelse stad, is in die ruimtelike dimensie reeds daar. Daar is wel nog uitsprake oor die eindverwagting, maar dit dien die paranese gerig aan die 'wanderende Gottesvolk'. Hierdie volk word voorberei vir '. . . die lange Zeit der Mühen und Leiden' (Conzelmann 1968: 342).

2.4.5 Die skrywer van die tweede Petrusbrief beroep hom in sy stryd teen dié wat met die paroesieverwagting spot, wel nog op die ou Naherwartung. Maar met die argument wat hy aanvoer, laat hy duidelik blyk dat hy self reeds die nabye verwagting prysgegee het.

2.4.6 By Johannes het die eskatologie meer as by enigiemand geword tot ' $n$ basies gerealiseerde eskatologie. Die nou van die geloof het die allerbelangrikste tydsmoment geword. En wie nou glo, lewe. Die oordeel het ook reeds met die koms van Jesus plaasgevind (Joh 3: 19). 'Für Johannes sind die Auferstehung Jesu, Pfingsten und die Parusia Jesu ein einziges Ereignis, und die Glaubenden haben schon jetzt das ewige Leben' (Bultmann 1965: 155). 
2.4.7 Die tyd van skrywe van die eerste Petrusbrief en die Openbaring van Johannes in ag genome, is dit aan die ander kant opvallend hoedat akute noodsituasies en vervolging die nabye eindverwagting weer laat opvlam het. Hier is die Naherwartung waarskynlik egter meer ' $n$ versugting as dat dit 'n oortuiging is.

Hierdie paar voobeelde behoort voldoende te wees om aan te toon waarvan ons praat wanneer temas uit die Nuwe Testament ter sprake gebring word.

\section{PRINSIPIËLE OORWEGINGS}

Wat moet nou in die lig van hierdie verskeidenheid as prinsipiële uitgangspunte geld wanneer ons oor Nuwe-Testamentiese temas sou preek? Is tema-prediking aan die hand van die Nuwe Testament haalbaar en legitiem en indien wel, hoe moet dit gedoen word? Dit lyk volkome toelaatbaar, en trouens wenslik, indien die volgende as voorwaardes en prinsipiële uitgangspunte sal geld:

3.1 Die feit van die bestaan van die verskeidenheid moet erken word.

3.2 Die verskeidenheid moet nie negatief beoordeel word nie, maar eerder (minstens tot op groot hoogte) gesien word as 'n rykdom en as die dinamiese resultaat van wat deur die Christus-gebeure gegenereer is.

3.3 Die verskeidenheid moet deurgaans só eerbiedig word dat elke korpus of konteks eers vir homself aan die woord moet kom.

3.4 Daar moet dus daarteen gewaak word dat die verskeidenheid gerelativeer of genivelleer word deur harmoniseringspogings.

3.5 Daar moet eweneens gewaak word teen die 'komplementêre' dwaling, naamlik dat veronderstel word dat wat teks $A$ van die tema sê, as komplementêr beskou kan word tot wat teks B daarvan sê, so asof die teologiese inhoud van 'n tema gelyk is aan die somtotaal van die onderskeie weergawes daarvan.

3.6 Dit beteken nie dat wat teks A sê, nie aangebied kan word as net so 'n legitieme verstaan van die tema as die betekenis wat teks B daaraan heg nie.

3.7 Dit beteken ook nie dat wat teks A en B gemeenskaplik oor die saak te sê het, nie verdiskonteer mag word nie, inteendeel.

3.8 Terwyl verstaanswyses oor ' $n$ tema wat mekaar nie weerspreek nie, naas mekaar aan die orde gestel kan word, is dit natuurlik 'n 
probleem in die geval van mekaar-weersprekendes. In hierdie geval is ' $n$ keuse onvermydelik.

3.9 Die keuse wat gemaak sal word, sal normaalweg gelei word deur die teologiese denkklimaat waarin die predikant hom bevind, maar dit mag nie daardeur voorgeskryf word nie.

3.10 Dit is in elk geval onvermydelik dat daar met ' $n$ kanon in die kanon gewerk sal word. Dit was en is trouens vanaf die vroegste tye en tot vandag toe die praktyk in die kerk. Daarvan is nie alleen die verskillende teologieë binne een kerk of kerkfamilie die bewys nie, maar ook die bestaan van verskillende denominasies. 'To recognize the canon of the NT is to affirm the diversity of Christianity' (Dunn 1977: 377).

3.11 Die keuse vir ' $n$ bepaalde verstaan van die tema of vir 'n sekere betekenisnuanse mag egter nie uitloop op 'n relativering of aftakeling van die Skrif nie. So 'n keuse kan en moet naamlik só in die prediking hanteer word dat die een teks nie teen die ander afgespeel word nie.

In die lig van hierdie prinsipiële uitgangspunte kan elke predikant self besluit hoe hy in die praktyk bepaalde temas in die prediking sal hanteer. Die raadsaamste sal wees om eers elke korpus afsonderlik aan die woord te stel en die eie van so 'n korpus rondom die tema uit te lig. Vir sover daar gemeenskaplikhede bestaan, kan dit dan telkens uitgewys word en uiteindelik kan dit samevattend as eenheidselemente aangebied word. Die indruk moet egter nie geskep word dat wat gemeenskaplik is, vanselfsprekend die kern van die tema uitmaak nie. Dit hoef nie noodwendig so te wees nie. Daar kan ook met die gemeenskaplike begin word en vervolgens beweeg word na die eiesoortige om so die verskeidenheid te midde van moontlike eenheid in reliëf te plaas. In gevalle waar die gemeenskaplike slegs geleë is in die tema as sodanig, sal vanselfsprekend slegs die verskeidenheid naas mekaar aan die orde kom.

\section{Literatuurverwysings}

BORNKAMM, G 1970. Herrenmahl und Kirche bei Paulus, in Studien zu Antike und Urchristentum: Gesammelte Aufsätze. München: Kaiser. (BzEvTh 28.)

BOUSSET, W 1967. Kyrios Christos: Geschichte des Christusglaubens von den Anfängen des Christentums bis Irenaeus. 6. Aufl. Göttingen: Vandenhoeck.

BULTMANN, R 1965. Jesus Christus und die Mythologie, in Glauben und Verstehen: Gesammelte Aufsätze IV, 141-189. Tübingen: Mohr.

CONZELMANN, H 1968. Grundriss der Theologie des Neuen Testaments. 2. Aufl. München: Kaiser. 
DUNN, JDG 1977. Unity and diversity in the New Testament: An inquiry into the character of earliest Christianity. London: SCM.

HAHN, F 1963.Christologische Hoheitstitel: Ihre geschichte im frühen Christentum. Göttingen: Vandenhoeck. (FRLANT.)

KÄSEMANN, E 1960. Begründet der neutestamentliche Kanon die Einheit der Kirche?, in Exegetische Versuche und Besinnungen I, 214-223. Göttingen: Vandenhoeck.

KINGSBURY, JD 1981. Jesus Christ in Matthew, Mark and Luke. Philadelphia: Fortress Press. (Proclamation commentaries.)

KRAMER, W 1963. Christos Kyrios Gottessohn. Zürich: Zwingli Verlag (Abh TANT 44.)

LOHSE, E 1982. Einheit und Vielfalt in der Kirche, in Die Vielfalt des Neuen Testaments: Exegetische Studien zur Theologie des Neuen Testaments II, 9-14. Göttingen: Vandenhoeck.

NINEHAM, D 1976. The use and abuse of the Bible: $A$ study of the Bible in an age of rapid cultural change. London: MacMillan. (Library of philosophy and religion.)

PELSER, GMM [1975]. Die nagmaal by Markus en Paulus: 'n Vergelykende studie. HTS 30, 138-149.

PELSER, GMM [1977]. Die nagmaal by Paulus - 'n geestelike voedsel en drank? HTS 32, $161-167$.

PELSER, GMM 1986. Resurrection andeschatology in Paul'sletters. Neotestamentica 20,36-45. 